\title{
Social inequality in coronary risk: central obesity and the metabolic syndrome. Evidence from the Whitehall II study
}

\author{
E. J. Brunner ${ }^{1}$, M. G. Marmot ${ }^{1}$, K. Nanchahal ${ }^{1}$, M. J.Shipley ${ }^{1}$, S. A.Stansfeld ${ }^{1}$, M. Juneja ${ }^{1}$, K. G. M. M. Alberti ${ }^{2}$ \\ ${ }^{1}$ International Centre for Health and Society, Department of Epidemiology and Public Health, University College London \\ Medical School, London, UK \\ ${ }^{2}$ Human Diabetes and Metabolism Research Centre, University of Newcastle-upon-Tyne, Newcastle-upon-Tyne, UK
}

\begin{abstract}
Summary This report describes the social distribution of central obesity and the metabolic syndrome at the Whitehall II study phase 3 examination, and assesses the contribution of health related behaviours to their distribution. Cross-sectional analyses were conducted utilising data collected in 1991-1993 from 4978 men and 2035 women aged 39-63 years who completed an oral glucose tolerance test. There was an inverse social gradient in prevalence of the metabolic syndrome. The odds ratio ( $95 \%$ confidence interval) for having the metabolic syndrome comparing lowest with highest employment grade was: men 2.2 (1.6-2.9), women 2.8 (1.6-4.8). Odds ratios for occupying the top quintile of the following variables, comparing lowest with highest grade, were, for waist-hip ratio: men 2.2 (1.8-2.8), women 1.6 (1.1-2.4); postload glucose: men 1.4 (1.1-1.8), women $1.8(1.2-2.6)$; triglycerides: men 1.6 (1.2-2.0), women 2.2 (1.5-3.3);
\end{abstract}

fibrinogen: men 1.7 (1.4-2.3), women 1.9 (1.2-2.8). Current smoking status, alcohol consumption and exercise level made a small contribution (men $11 \%$, women $9 \%$ ) to the inverse association between socioeconomic status and metabolic syndrome prevalence. In conclusion, central obesity, components of the metabolic syndrome and plasma fibrinogen are strongly and inversely associated with socioeconomic status. Our findings suggest the metabolic syndrome may contribute to the biological explanation of social inequalities in coronary risk. Health related behaviours appear to account for little of the social patterning of metabolic syndrome prevalence. [Diabetologia (1997) 40: 1341-1349]

Keywords Socioeconomic factors, coronary disease, waist-hip ratio, insulin resistance, glucose intolerance, lipoproteins, fibrinogen.
The better the socioeconomic position of an individual, the lower is the risk of premature coronary heart disease. An array of studies have documented this linkage [1-4], but only limited attention has been paid to the biological explanation for this acknowledged public health problem $[5,6]$. Smoking accounts for some but not all of this social gradient in coronary disease $[1,7,8]$. Serum total cholesterol levels are similar across social strata $[3,9,10]$, and resting

Received: 5 February 1997 and in revised form: 11 June 1997

Corresponding author: Dr. E. Brunner, International Centre for Health and Society, Department of Epidemiology and Public Health, University College London Medical School, 1-19 Torrington Place, London WC1E 6BT, UK

Abbreviations: vWF, von Willebrand factor. mean blood pressure level shows only a small differential in the expected direction $[3,10,11]$.

Although the classical risk factors fail to account for social inequalities in coronary disease, we have demonstrated that plasma fibrinogen, and its determinants, may be important [12]. It may also be that the abdominal pattern of fat distribution is implicated. A high waist-hip ratio is a marker for increased risk of coronary disease [13-16] and non-insulin-dependent diabetes mellitus (NIDDM) $[17,18]$. Central obesity is linked with features of the metabolic syndrome, or Reaven's syndrome X $[19,20]$, impaired glucose tolerance, insulin resistance and raised serum triglycerides, and low levels of HDL cholesterol. Studies of South Asian communities in Britain [18] suggest that central obesity and associated metabolic disturbances involving glucose, insulin and lipids 
underlie the excess coronary disease rates experienced by these ethnic groups.

In order to test the hypothesis that the metabolic syndrome contributes to the explanation of social inequalities in coronary risk, the second medical examination (1991-1993) of the Whitehall II cohort included a $2 \mathrm{~h} 75 \mathrm{~g}$ oral glucose tolerance test and measurements of waist and hip circumferences. This report presents the distribution of NIDDM, impaired glucose tolerance, anthropometric and biochemical factors including lipoprotein(a), according to Civil Service employment grade, which is a sensitive measure of social position, and examines the behavioural correlates of the metabolic syndrome. The second examination involved measurements of fibrinogen and a second acute-phase reactant, von Willebrand factor, on the whole cohort [21].

\section{Subjects and methods}

Participants. Demographic and psychosocial characteristics, health and risk factor status of the 10308 participants at baseline are published $[3,22]$. Subjects were recruited in 19851988 (Phase 1) from 20 London-based Civil Service departments. The response rate was $73 \%$ but detailed investigation in one department showed that $4 \%$ of those present on the list of employees had moved prior to our study, and so the true response rate is likely to be higher. The data presented are from Phase 3 (1991-1993), involving examination of 5616 men and 2488 women aged $39-63$ years.

South Asian and Afro-Caribbean subjects have been excluded from the analyses. In these groups coronary risk does not show the inverse social gradient evident in adults of European origin [23] which this paper examines. A further 286 subjects of unspecified ethnic origin were excluded, yielding 7013 European subjects ( 4978 men, 2035 women). Current use of drugs affecting the cardiovascular system was reported by $3.7 \%$ of men and $5.9 \%$ of women. $\beta$-Adrenoceptor antagonists were most commonly reported $(137(2.8 \%)$ men, $67(3.3 \%)$ women), followed by thiazide diuretics $(33(0.7 \%)$ men, 53(2.6\%) women). Exclusion of these subjects did not materially change the results and this group was retained for the analyses.

Screening examination. All measurements were carried out according to a standard protocol [24]. Body circumferences were measured with subjects in the standing position and unclothed, utilizing a fibreglass tape-measure at $600 \mathrm{~g}$ tension. The waist circumference was taken as the smallest circumference at or below the costal margin and the hip circumference at the level of the greater trochanter. The oral glucose tolerance test was administered following an overnight fast or in the afternoon after no more than a light fat-free breakfast eaten before 08.00 hours. After the initial venous blood sample, participants drank $389 \mathrm{ml}$ 'Lucozade' (equivalent to $75 \mathrm{~g}$ anhydrous glucose) over 5 min. A second blood sample was taken $2 \mathrm{~h}$ later. Diabetic subjects did not participate in this part of the screening.

Venepuncture of the left antecubital vein was performed with tourniquet. Blood was collected into plain, citrate or fluoride Sarstedt monovettes. After centrifugation samples were immediately frozen at $-80^{\circ} \mathrm{C}$ and stored until assay. Serum for lipid analysis was refrigerated at $-4^{\circ} \mathrm{C}$ and assayed within
$72 \mathrm{~h}$. Glucose was determined in fluoride plasma by an electrochemical glucose oxidase method. Serum insulin was measured by radioimmunoassay using a polyclonal guinea-pig antiserum. Cholesterol and triglycerides were measured in a centrifugal analyser by enzymic colorimetric methods. HDL cholesterol was determined after dextran sulphate-magnesium chloride precipitation of non-HDL cholesterol. LDL cholesterol level was derived from the Friedewald equation [25]. External comparisons and examination of age differences at Phases 1 and 3 show that serum cholesterol levels were over-estimated by approximately $0.33 \mathrm{mmol} / \mathrm{l}$ at follow-up. Lipoprotein(a), and apolipoproteins AT and B were determined by immunoturbidimetric methods. Fibrinogen was determined by an automated modification of the Clauss method [24]. von Willebrand factor (vWF) factor antigen was measured by double antibody ELISA. Technical error was estimated by assaying blinded duplicate samples for $5 \%$ of subjects. Coefficients of variation were $2.0-6.6 \%$ for glucose, cholesterol, triglycerides and HDL cholesterol, $23 \%$ for insulin, $16.4 \%$ for vWF and $7.7 \%$ for fibrinogen.

Repeated measures. A sub-sample of 323 subjects returned after 2-4 weeks in order to estimate reliability (between-person variability as a proportion of total variability). Reliability for the anthropometry, estimated by intra-class correlations, was 0.93 or better except for hip circumference in women $(0.86)$. Intra-class correlations for fasting glucose and insulin were respectively 0.58 and 0.52 , and for $2 \mathrm{~h}$ samples 0.66 and 0.58 , for lipid measurements $0.78-0.97$, for vWF 0.75 and for fibrinogen 0.50 in men and 0.72 in women. Multilevel modelling (MLn) showed that diurnal variation was a source of variance in the glucose tolerance test results. For $2 \mathrm{~h}$ values of glucose and insulin respectively 8.7 and $6 \%$ of between-subject variation, and 10.3 and $4.9 \%$ of within-subject variation was attributable to time of sample. This effect was controlled for by adjusting fasting and post-load glucose and insulin to a sample time of 12.00 hours.

Questionnaire and grade of employment. Participants completed a machine-readable questionnaire which was checked for completeness and validity. An interviewer elicited missing responses. Participants reported their Civil Service grade title, which was assigned to 1 of 6 grades based on salary scale. Grade 1 consists of subjects in Unified Grades 1-6 (annual salary range at 1 August $1992, £ 28904-87620$ ), grade 2 is equivalent to Unified Grade 7 ( $£ 25330-36019$ ), grade 3 is Senior Executive Officer ( $£ 18082-25554)$, grade 4 is Higher Executive Officer ( $£ 14456-20850$ ), grade 5 Executive Officer ( $£ 8517-$ $16,668)$ and grade 6 Clerical and Office Support staff (£ 648311 917).

Glucose tolerance. Impaired glucose tolerance was defined according to World Health Organisation criteria [26] as a $2 \mathrm{~h}$ post-load glucose of $7.8-11.0 \mathrm{mmol} / \mathrm{l}$. Diabetic subjects were defined as known and newly diagnosed cases, identified from questionnaire responses ('Do you suffer from diabetes: yes/ no', diabetic eye disease, or current use of oral hypoglycaemic drugs) or a post-load glucose $\geq 11.1 \mathrm{mmol} / \mathrm{l}$ (or, if missing, a fasting glucose $\geq 7.8 \mathrm{mmol} / \mathrm{l}$ ). In normoglycaemic subjects only, the post-load insulin concentration was taken as an index of insulin resistance [27].

Definition of the metabolic syndrome. Prevalence of the metabolic syndrome was defined on the basis of clustering of risk factors according to their sex-specific distributions. Individuals were considered to have the metabolic syndrome when three or more of the following were in the top sex-specific quintile: $2 \mathrm{~h}$ glucose, systolic blood pressure, fasting triglycerides, HDL 
Table 1. Definition of metabolic syndrome. Cut-off points for the sex-specific top quintile, or bottom quintile in the case of HDL cholesterol. Subjects are defined as exhibiting the metabolic syndrome if 3 or more cut-off points are exceeded

\begin{tabular}{lll}
\hline Variable & Men & Women \\
\hline Post-load glucose $^{\mathrm{a}}(\mathrm{mmol} / \mathrm{l})$ & $>6.30$ & $>6.74$ \\
Systolic blood pressure $^{\mathrm{b}}(\mathrm{mm} \mathrm{Hg})$ & $>132.0$ & $>129.0$ \\
Fasting triglycerides $(\mathrm{mmol} / \mathrm{l})$ & $>2.11$ & $>1.56$ \\
Fasting HDL cholesterol $(\mathrm{mmol} / \mathrm{l})$ & $<1.03$ & $<1.34$ \\
Waist-hip ratio & $>0.952$ & $>0.821$ \\
\hline
\end{tabular}

${ }^{a}$ Post-load glucose values adjusted to midday. Cut-off point excludes known diabetic subjects

${ }^{\mathrm{b}}$ Cut-off point excludes treated hypertensive subjects

See Methods section for details

Table 2. Demographic and behavioural characteristics, and glucose tolerance status of the study population

\begin{tabular}{|c|c|c|c|c|}
\hline & \multicolumn{2}{|l|}{ Men } & \multicolumn{2}{|l|}{ Women } \\
\hline & Percent & Number & Percent & Number \\
\hline $\begin{array}{l}\text { Total } \\
\text { Age group (years) }\end{array}$ & & 4978 & & 2035 \\
\hline $39-44$ & 28.4 & 1413 & 23.7 & 482 \\
\hline $45-49$ & 29.0 & 1446 & 24.3 & 495 \\
\hline $50-54$ & 19.0 & 948 & 20.9 & 425 \\
\hline $55-63$ & 23.5 & 1171 & 31.1 & 633 \\
\hline \multicolumn{5}{|l|}{ Employment grade } \\
\hline 1 (high) & 23.0 & 1124 & 7.0 & 127 \\
\hline 2 & 27.5 & 1340 & 10.9 & 218 \\
\hline 3 & 17.7 & 864 & 9.2 & 184 \\
\hline 4 & 17.9 & 871 & 16.4 & 327 \\
\hline 5 & 8.6 & 421 & 22.8 & 456 \\
\hline 6 (low) & 5.3 & 257 & 33.7 & 675 \\
\hline \multicolumn{5}{|l|}{ Smoking status } \\
\hline never smoker & 48.4 & 2322 & 51.4 & 1000 \\
\hline ex-smoker & 39.2 & 1881 & 29.9 & 581 \\
\hline current smoker & 12.4 & 595 & 18.7 & 363 \\
\hline \multicolumn{5}{|l|}{ Alcohol intake } \\
\hline none & 13.0 & 632 & 25.8 & 516 \\
\hline low/moderate & 68.0 & 3311 & 63.5 & 1268 \\
\hline high & 19.0 & 927 & 10.7 & 214 \\
\hline \multicolumn{5}{|l|}{ Physical activity } \\
\hline none/mild & 13.2 & 642 & 32.1 & 643 \\
\hline moderate & 46.2 & 2254 & 49.5 & 990 \\
\hline vigorous & 40.7 & 1986 & 18.4 & 367 \\
\hline \multicolumn{5}{|l|}{ Glucose tolerance } \\
\hline normal & 90.6 & 4287 & 88.0 & 1691 \\
\hline impaired & 7.6 & 357 & 9.8 & 189 \\
\hline diabetic & 1.9 & 88 & 2.2 & 42 \\
\hline
\end{tabular}

${ }^{a}$ High alcohol intake categories, men: over 21 units per week; women: over 14 units per week

cholesterol (bottom quintile) and waist-hip ratio (Table 1). Subjects taking hypotensive medication were assigned to the highest blood pressure quintile, and known diabetic patients to the highest $2 \mathrm{~h}$ glucose quintile. Inclusion of $2 \mathrm{~h}$ insulin among the variables produced similar results in analyses by grade, but was not considered to be a good proxy for insulin resistance [27]. Among glucose intolerant subjects, $49.4 \%$ of men and $44.7 \%$ of women were not in the top insulin quintile. Clustering of unfavourable levels of these variables was demonstrated with grade of membership models [28] and principal components analysis. In both sexes, these methods identified two associated risk factor clusters: glucose, insulin and blood pressure, and triglycerides, HDL cholesterrol and waist-hip ratio.

Statistical analysis was performed using SAS computer software (SAS, Cary, N. C., USA). Biochemical variables were $\log$ transformed. For age adjustment linear regression or logistic regression was used, holding age to its whole sample mean of approximately 50 years. Among women, an interaction term for age and menopausal status was included. Probabilities for occupying the top quintile according to employment grade were determined by logistic regression. Tests of trend or heterogeneity were based on regression analysis with the relevant factor entered respectively as a continuous or categorical variable with age as a covariate. Initially grade was treated as a categorical variable with 6 levels and odds ratios estimated relative to the highest grade level. These analyses showed the odds ratios generally increased monotonically across the grades. To improve precision, therefore, odds ratios of lowest versus highest grade were estimated with grade entered as a continuous variable.

\section{Results}

Demographic and behavioural characteristics, and glucose tolerance status of the study population at phase 3 are shown in Table 2. Higher employment grades tend to be occupied by men, and the lower grades by women. Less than $20 \%$ of respondents reported being current smokers. Women were more likely than men to say they were non-drinkers. Among drinkers, men tended to report a higher alcohol intake than women. Habitual vigorous physical activity (more than $1 \mathrm{~h}$ per week) was reported by approximately twice as many men as women.

Mean \pm SD body-mass index was $25.2 \pm 3.2 \mathrm{~kg} / \mathrm{m}^{2}$ in men and $25.4 \pm 4.6 \mathrm{~kg} / \mathrm{m}^{2}$ in women. The mean \pm SD waist-hip ratio was $0.902 \pm 0.061$ in men and $0.770 \pm 0.069$ in women. Whitehall II subjects tended to have a lower degree of obesity and to be somewhat less centrally obese than groups of a similar age sampled from the general population [10]. Body-mass index and waist-hip ratio were moderately associated (age-adjusted partial correlations: men 0.66 , women 0.55 ; both $p<0.0001$ ).

Age and, in women, menopause adjusted means by employment grade for anthropometric and biochemical measures are shown in Tables 3 and 4 . In general, there were linear trends across grades with the lowest grades having the more adverse levels. There was no trend by grade in mean hip circumference in men or women and therefore grade differences in mean waist-hip ratio were produced mainly by variation in waist circumference. Grade differences in glucose and insulin levels tended to be small in the fasting state, and larger after the glucose load. Among women the trend in mean $2 \mathrm{~h}$ insulin was essentially linear, but the probability of having a level in the top quintile showed substantial non-linearity, with a similar prevalence in the top administrative grade as in the clerical category (Fig.1). Mean fasting 
Table 3. Anthropometric and biochemical data: men. Mean values by Civil Service employment grade adjusted for age

\begin{tabular}{|c|c|c|c|c|c|c|c|c|}
\hline & \multicolumn{8}{|c|}{ Employment grade } \\
\hline & $\begin{array}{l}1 \\
\text { highest }\end{array}$ & 2 & 3 & 4 & 5 & $\begin{array}{l}6 \\
\text { lowest }\end{array}$ & $\begin{array}{l}\text { Total } \\
\text { sample }\end{array}$ & $\begin{array}{l}\text { Test for } \\
\text { trend }\end{array}$ \\
\hline Height (cm) & 178.0 & 176.9 & 176.8 & 176.5 & 175.3 & 173.6 & 4969 & 0.0001 \\
\hline Weight (kg) & 79.4 & 78.6 & 78.8 & 78.9 & 78.0 & 77.8 & 4970 & 0.02 \\
\hline $\mathrm{BMI}\left(\mathrm{kg} / \mathrm{m}^{2}\right)$ & 24.9 & 24.9 & 25.0 & 25.1 & 25.1 & 25.5 & 4965 & 0.004 \\
\hline Waist $(\mathrm{cm})$ & 87.3 & 87.3 & 87.7 & 88.2 & 88.1 & 89.5 & 4978 & 0.0003 \\
\hline $\mathrm{Hip}(\mathrm{cm})$ & 97.4 & 96.9 & 97.0 & 97.1 & 96.6 & 97.0 & 4978 & NS \\
\hline Waist-hip ratio & 0.896 & 0.900 & 0.903 & 0.907 & 0.910 & 0.919 & 4978 & 0.0001 \\
\hline Systolic BP $(\mathrm{mm} \mathrm{Hg})$ & 122 & 121 & 121 & 122 & 121 & 123 & 4963 & - \\
\hline Diastolic BP $(\mathrm{mm} \mathrm{Hg})$ & 81 & 81 & 81 & 81 & 82 & 82 & 4963 & - \\
\hline Cholesterol (mmol/l) & 6.38 & 6.37 & 6.41 & 6.39 & 6.43 & 6.52 & 4941 & NS \\
\hline LDL cholesterol $(\mathrm{mmol} / \mathrm{l})$ & 4.4 & 4.3 & 4.4 & 4.3 & 4.4 & 4.4 & 4817 & NS \\
\hline HDL cholesterol (mmol/l) & 1.32 & 1.27 & 1.27 & 1.26 & 1.26 & 1.24 & 4922 & 0.0001 \\
\hline Triglycerides $(\mathrm{mmol} / \mathrm{l})$ & 1.25 & 1.36 & 1.36 & 1.40 & 1.40 & 1.53 & 4941 & 0.0001 \\
\hline Lipoprotein(a) (mg/dl) & 20.7 & 21.9 & 21.0 & 21.6 & 21.4 & 23.9 & 4939 & NS \\
\hline Apolipoprotein AI (mg/dl) & 206.4 & 202.2 & 203.0 & 202.5 & 202.5 & 201.7 & 4941 & 0.01 \\
\hline Apolipoprotein B (mg/dl) & 127.3 & 128.1 & 128.8 & 127.8 & 129.1 & 131.5 & 4941 & NS \\
\hline Fasting glucose $(\mathrm{mmol} / \mathrm{l})$ & 5.3 & 5.2 & 5.3 & 5.3 & 5.2 & 5.3 & 4688 & NS \\
\hline $2 \mathrm{~h}$ glucose $(\mathrm{mmol} / \mathrm{l})$ & 5.0 & 5.1 & 5.1 & 5.0 & 5.2 & 5.1 & 4687 & NS \\
\hline Fasting insulin (pmol/1) & 30.6 & 31.2 & 31.2 & 33.0 & 34.8 & 34.8 & 4414 & 0.0001 \\
\hline $2 \mathrm{~h}$ insulin $(\mathrm{pmol} / \mathrm{l})$ & 154.8 & 164.4 & 170.4 & 166.8 & 176.4 & 181.8 & 4671 & 0.001 \\
\hline Fibrinogen $(\mathrm{g} / \mathrm{l})$ & 2.24 & 2.28 & 2.29 & 2.31 & 2.31 & 2.42 & 4615 & 0.0001 \\
\hline von Willebrand (IU/ml) & 97.9 & 100.0 & 101.0 & 102.2 & 101.2 & 107.1 & 4477 & 0.0002 \\
\hline
\end{tabular}

${ }^{a}$ Medians

Table 4. Anthropometric and biochemical data: women. Mean values by Civil Service employment grade adjusted for age and menopausal status

\begin{tabular}{|c|c|c|c|c|c|c|c|c|}
\hline & \multicolumn{8}{|c|}{ Employment grade } \\
\hline & $\begin{array}{l}1 \\
\text { highest }\end{array}$ & 2 & 3 & 4 & 5 & $\begin{array}{l}6 \\
\text { lowest }\end{array}$ & $\begin{array}{l}\text { Total } \\
\text { sample }\end{array}$ & $\begin{array}{l}\text { Test for } \\
\text { trend }\end{array}$ \\
\hline Weight (kg) & 67.9 & 66.7 & 68.9 & 67.6 & 67.4 & 67.6 & 1997 & NS \\
\hline BMI $\left(\mathrm{kg} / \mathrm{m}^{2}\right)$ & 24.7 & 24.4 & 25.1 & 25.2 & 25.2 & 25.7 & 1996 & 0.0001 \\
\hline Waist (cm) & 74.9 & 74.2 & 74.9 & 75.5 & 74.9 & 76.5 & 1997 & 0.02 \\
\hline Systolic BPa $(\mathrm{mm} \mathrm{Hg})$ & 112 & 118 & 115 & 117 & 117 & 115 & 2034 & - \\
\hline Diastolic BPa (mm Hg) & 74 & 76 & 76 & 76 & 77 & 75 & 2034 & - \\
\hline Cholesterol $(\mathrm{mmol} / \mathrm{l})$ & 6.37 & 6.50 & 6.38 & 6.38 & 6.43 & 6.44 & 1980 & NS \\
\hline LDL cholesterol $(\mathrm{mmol} / \mathrm{l})$ & 4.0 & 4.1 & 4.1 & 4.0 & 4.2 & 4.2 & 1969 & 0.008 \\
\hline HDL cholesterol (mmol/l) & 1.80 & 1.80 & 1.70 & 1.68 & 1.65 & 1.56 & 1980 & 0.0001 \\
\hline Triglycerides $(\mathrm{mmol} / \mathrm{l})$ & 0.98 & 0.99 & 0.99 & 1.09 & 1.07 & 1.14 & 1980 & 0.0001 \\
\hline Lipoprotein(a) (mg/dl) & 20.2 & 19.9 & 19.4 & 18.9 & 20.5 & 23.3 & 1980 & 0.009 \\
\hline Fasting insulin $(\mathrm{pmol} / \mathrm{l})$ & 29.4 & 25.2 & 28.8 & 28.2 & 28.2 & 30.6 & 1720 & 0.02 \\
\hline $2 \mathrm{~h}$ insulin $(\mathrm{pmol} / \mathrm{l})$ & 220.2 & 222.0 & 224.4 & 260.4 & 257.4 & 270.6 & 1879 & 0.0001 \\
\hline Fibrinogen $(\mathrm{g} / \mathrm{l})$ & 2.35 & 2.33 & 2.36 & 2.43 & 2.52 & 2.52 & 1890 & 0.0001 \\
\hline von Willebrand (IU/ml) & 94.9 & 93.2 & 94.0 & 98.1 & 101.4 & 102.7 & 1792 & 9.0001 \\
\hline
\end{tabular}

${ }^{\text {a Medians }}$

serum triglyceride and HDL cholesterol levels were strongly related to grade in the expected directions. Mean serum cholesterol levels did not differ by grade category, as at the Whitehall II baseline [3], but there was an association with grade of LDL cholesterol in women which was absent in men (grade by sex interaction $p<0.001$ ). Mean lipoprotein(a) levels were inversely related to employment grade in women, and among men (trend $p=0.1$ ) the mean level was highest in the clerical category. There was a trend to more favourable levels of apolipoprotein $\mathrm{AI}$ in higher grades in both sexes, as was the case with HDL cholesterol. The apolipoprotein B level, like LDL cholesterol, was related to grade in the expected 

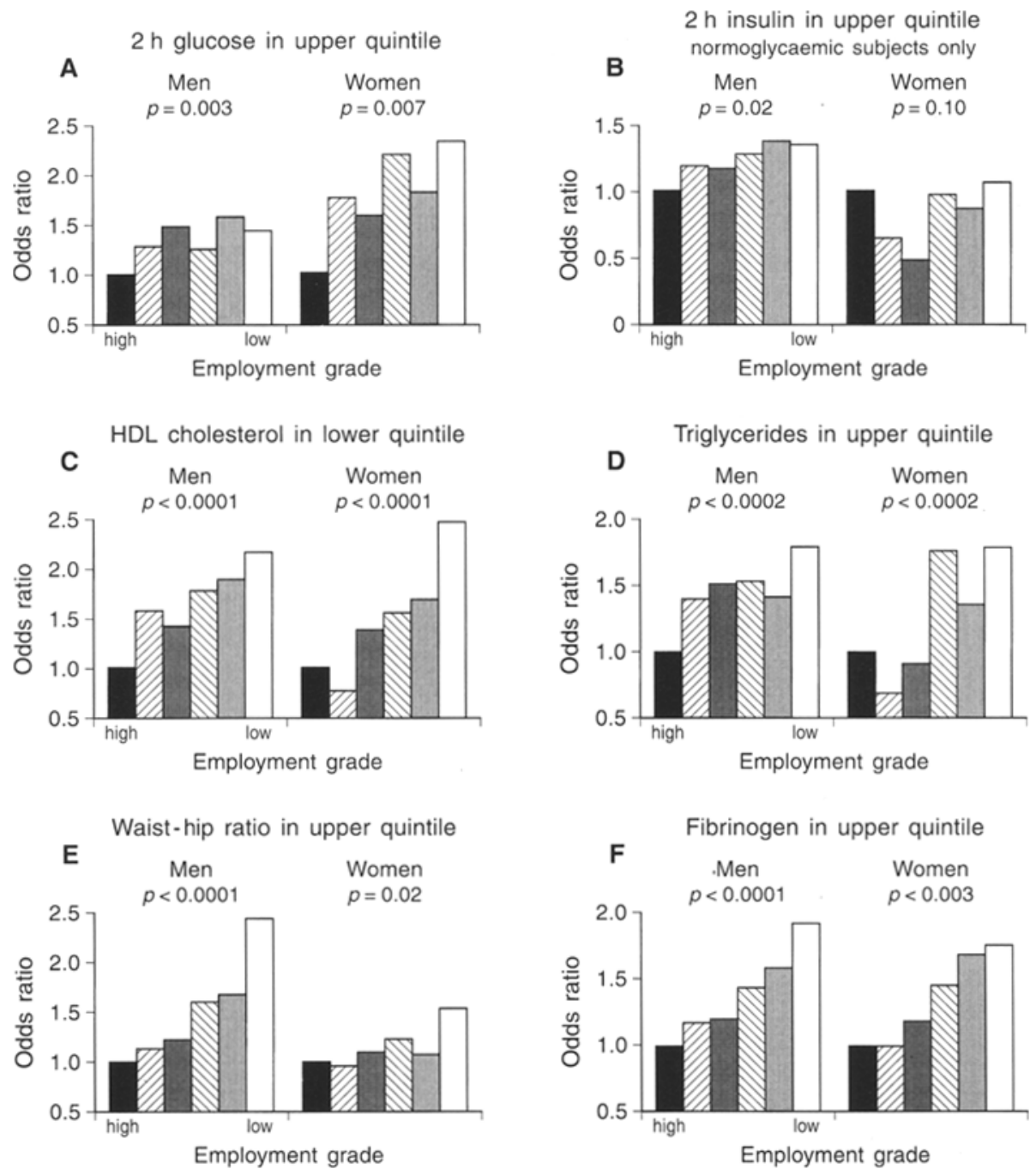

Fig.1A-F. Adjusted odds ratios for occupying the top quintile of anthropometric and biochemical variables by grade after adjustment for age and, in women, menopausal status. $P$ values are for trend tests across employment grade categories. (A) $2 \mathrm{~h}$ post-load glucose; (B) $2 \mathrm{~h}$ post-load insulin for normoglycaemic subjects; (C) fasting serum HDL-cholesterol (bottom quintile); (D) fasting serum triglycerides; (E) waist-hip ratio; (F) plasma fibrinogen

direction only among women (grade by sex interaction $p<0.001$ ). Mean fibrinogen levels were inversely related to employment grade in both sexes, replicating findings at Phase 1 [12]. Systolic blood pressure was not associated with employment grade (Tables 3 and 4) but was significantly correlated with waist-hip ratio (age-adjusted partial correlations: men 0.21, women 0.17 , both $p<0.001$ ).

Odds ratios for occupying the least favourable quintile of the metabolic syndrome related variables and plasma fibrinogen for each grade relative to the highest grade are shown in Figure 1. Strong trends across employment grades are seen for most of these

variables. The sizes of the generally monotonic trends are summarised in Table 5. Large differentials were observed in both sexes for waist-hip ratio, HDL cholesterol and fibrinogen. $549(11.7 \%$ of 4691$)$ men and $234(12.2 \%$ of 1916$)$ women fulfilled the criteria for the metabolic syndrome, as defined (Table 1). Odds ratios for having the metabolic syndrome by employment grade are shown in Figure 2. The odds ratio for having the syndrome in the lowest compared to the highest grade was 2.16 for men and 2.75 for women. Removing $2 \mathrm{~h}$ glucose from the set of variables used to define the metabolic syndrome (as if a glucose tolerance test had not been conducted) yielded a prevalence of $7.6 \%$ in men and $8.7 \%$ in women. The odds ratio for having the metabolic syndrome by grade using this definition was $2.20(1.53-3.17$, trend $p<0.0001)$ in men and $3.63(1.85-7.14$, trend $p<0.005$ ) in women.

The associations of the metabolic syndrome with body-mass index, smoking status, alcohol consumption and physical exercise are shown in Table 6. Degree of obesity was highly associated with prevalence of the metabolic syndrome. In contrast, smoking 
Table 5. Odds ratios (95\% confidence interval) for occupying top quintile of metabolic syndrome variables and plasma fibrinogen, lowest versus highest Civil Service employment grade.

\begin{tabular}{lllll}
\hline Variable & Men & trend $p$ & Women & trend $p$ \\
\hline Metabolic syndrome & $2.16(1.61-2.90)$ & $<0.0001$ & $2.75(1.59-4.75)$ & $<0.005$ \\
Waist-hip ratio & $2.23(1.76-2.82)$ & $<0.0001$ & $1.62(1.09-2.39)$ & $<0.05$ \\
Body-mass index & $1.62(1.28-2.05)$ & $<0.0001$ & $1.55(1.06-2.28)$ & $<0.05$ \\
Systolic BP & $1.21(0.97-1.51)$ & NS & $1.12(0.77-1.63)$ & NS \\
2 h glucose & $1.43(1.12-1.83)$ & $<0.005$ & $1.72(1.17-2.55)$ & $<0.05$ \\
2 h insulin $^{\text {a }}$ & $1.37(1.04-1.80)$ & $<0.05$ & $1.46(0.93-2.30)$ & 0.1 \\
HDL cholesterol $^{b}$ & $1.93(1.53-2.45)$ & $<0.0001$ & $3.00(2.01-4.49)$ & $<0.0001$ \\
LDL cholesterol $_{\text {Triglycerides }}^{1.03(0.80-1.31)}$ & NS & $1.43(0.96-2.14)$ & 0.08 \\
Fibrinogen & $1.56(1.23-1.97)$ & $<0.005$ & $2.19(1.45-3.31)$ & $<0.005$ \\
\hline
\end{tabular}

Adjusted for age, and menopausal status in women; ${ }^{a}$ Normoglycaemic subjects only; ${ }^{\mathrm{b}}$ bottom quintile; NS $p>0.1 ;$ See Table 1 for definition of metabolic syndrome

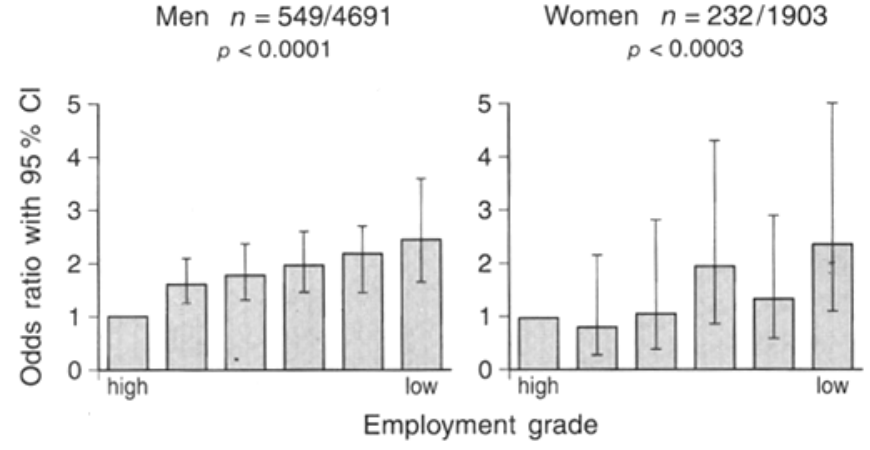

Fig.2. Adjusted odds ratios for metabolic syndrome by grade after adjustment for age and, in women, menopausal status. $P$ values are for trend tests across employment grade categories ${ }^{1}$

${ }^{1}$ See Table 1 for definition of metabolic syndrome. Two women had missing data on menopausal status.

Table 6. Odds ratios for having metabolic syndrome according to body mass index and health related behaviours

\begin{tabular}{lccll}
\hline Variable & Men & $p$ value & Women & $p$ value \\
\hline $\begin{array}{l}\text { Body-mass index } \\
\left(\mathrm{kg} / \mathrm{m}^{2}\right)\end{array}$ & & & \\
$<24.9$ & 1 & $<0.0001$ & 1 & $<0.0001$ \\
$25-29.9$ & 4.95 & & 5.70 & \\
$\geq 30$ & 15.8 & & 18.9 & \\
$\begin{array}{l}\text { Smoking status } \\
\text { never smoker }\end{array}$ & 1 & $<0.05$ & 1 & $\mathrm{NS}$ \\
ex-smoker & 1.27 & & 1.14 & \\
$\begin{array}{l}\text { current smoker } \\
\text { Alcohol intake }\end{array}$ & 1.35 & & 1.13 & \\
none & 1 & & & \\
$\begin{array}{l}\text { low/moderate } \\
\text { high }\end{array}$ & 0.81 & $\mathrm{NS}$ & 0.61 & $<0.005$ \\
$\begin{array}{l}\text { Physical activity } \\
\text { none/mild }\end{array}$ & 1.00 & $\mathrm{NS}$ & 0.64 & $\mathrm{NS}$ \\
moderate & 1 & & & \\
vigorous & 0.88 & $<0.005$ & 1 & $\mathrm{NS}$ \\
\hline Adjusted for age & 0.65 & & 0.97 & \\
\hline
\end{tabular}

Adjusted for age, and menopausal status in women.

Chi-square tests for trend, except for alcohol for which heterogeneity test was utilized status and physical activity level were weakly or not at all associated with the metabolic syndrome. Among women, low/moderate alcohol consumers (1-14 units/week) had a low probability of exhibiting the syndrome.

Logistic regression analysis was performed with the metabolic syndrome as the dependent variable, employment grade (6 level continuous variable) as the predictor variable, and age group, and menopausal status in women as the adjustment variables. Adjustment for behavioural factors (smoking status, alcohol consumption and exercise level) had little effect on the grade gradient, reducing it by $11 \%$ in men and $9 \%$ in women. Adjustments for body-mass index as well as behavioural factors produced attenuations of $33 \%$ in men and $10 \%$ in women.

There is interest in the degree of involvement of the haemostatic system in the metabolic syndrome $[20,21]$. Fibrinogen levels were directly associated with waist-hip ratio (men $R=0.17$, women $R=0.20$; both $p<0.0001$ ), with fasting insulin among normoglycaemics (men 0.12 , women 0.21 ; both $p<0.0001$ ) and inversely associated with HDL cholesterol (men -0.18 , women -0.22 ; both $p<0.0001$ ).

\section{Discussion}

Central or abdominal obesity, long recognised as a factor predisposing to diabetes and coronary disease [29] in both sexes, is linked with glucose intolerance, insulin resistance and disturbances of lipoprotein metabolism [30, 31]. Each of these components of the metabolic syndrome showed a close inverse association with employment grade in the Whitehall II data. Clustering of risk factors into the characteristic metabolic syndrome pattern was strongly associated with lower grade in both men (odds ratio $=2.2$ ) and women (odds ratio $=2.8$ ). For comparison, 10-year coronary mortality in the first Whitehall study in the clerical grade was 2.3-fold greater than that among administrators [32]. In the absence of marked 
differentials in serum total cholesterol $[3,9,10]$ or blood pressure [11], our findings thus suggest a biological explanation for the increasing risk of coronary disease as the social strata are descended $[4,33]$.

Visceral fat is the critical fat depot related to the metabolic syndrome [13-20]. The extent to which the findings for central obesity and socioeconomic status might be generalised was investigated by collecting data from 13 population-based surveys in Britain, mainland Europe and the USA (references available from author). Nine of 12 surveys among men, and 11 of 13 among women showed an inverse relation between socioeconomic status and waist-hip ratio. Associations between low socioeconomic status and low levels of HDL cholesterol have been reported [9, 34, 35 , and as in our data, tend to be stronger among women than men. Here we have been able to carry out a detailed cross-sectional study of anthropometry, lipid metabolism and glucose tolerance in a cohort set up to examine socioeconomic status and chronic disease. Our pragmatic definition of the metabolic syndrome, based on clinical observation $[19,20]$ and supported by multivariate analyses, has identified approximately equal proportions of men $(11.7 \%)$ and women $(12.2 \%)$ who meet the criteria. Our use of sex-specific quintiles for the component variables constrains women to have approximately the same prevalence of 'abnormality' as men. If, in fact, the syndrome is less prevalent in women [36] our definition of abnormal may misclassify more women than men. It may be for this reason that the association between metabolic syndrome and employment grade is less linear among women than men. It may also be that the influence of employment grade is mediated by different factors among women and men.

The effects of social status on risk of premature mortality and ill-health are not restricted to individuals in poverty, whose deprived living conditions are linked with the largest health deficit [37]. A stepwise increase in the experience of preventable ill-health extends downwards across the social spectrum. For example, relatively well-paid and highly-educated employees in Civil Service executive grades are more likely than their more senior administrative colleagues, and less likely than their clerical colleagues, to exhibit prevalent electrocardiographic ischaemia [3]. These crucial observations suggest that psychosocial influences, as well as an adequate level of material security, are important in explanations of the social gradient in ill health $[38,39]$.

The inverse occupational gradient in the metabolic syndrome was little altered by taking account of current reported smoking, alcohol consumption and exercise level. The effect of physical activity may be underestimated due to our imprecise assessment of this complex behaviour. Further, dietary composition has not been taken into consideration in these analyses. Another more precisely measured behaviour-related variable, degree of obesity, was strongly related to metabolic syndrome prevalence (Table 6), but when all of these factors were statistically accounted for a considerable occupational gradient in metabolic syndrome remained. This finding is consistent with the operation of other potentially important influences on coronary risk [12].

Our striking anthropometric and metabolic findings may be evidence of psychosocial influences $[6$, 40]. Financial strain [41], job insecurity [42], low perceived control at work [12], stressful life events and poor social networks, depression [43, 44] and low self-esteem [44] are each a function of social status, and these may be translated to effects on body systems regulated by the central nervous system. Findings from human and animal studies indicate that central obesity, glucose intolerance, hypertension and disturbances of lipoprotein metabolism may be promoted by the activity of the hypothalamic-pituitary-adrenal axis [40] and perhaps other pathways [45] which link perception and cognition with physiological processes. Congruent with this, hostility, assessed by the Cook-Medley/MMPI questionnaire [46] and financial problems were found to be associated with waist-hip ratio in each of the four race/sex groups in the CARDIA study of young adults [47].

Remarkably, the same lipoprotein and apolipoprotein gradients observed by employment grade in male Civil Servants [22] are observed among male baboons according to dominance: low status-low HDL cholesterol and apolipoprotein AI, and no difference in the LDL fraction. Sapolsky and Mott [48] showed that higher ranking male baboons had lower morning cortisol levels, and that, overall, cortisol was inversely correlated with HDL cholesterol and apoAI concentrations. In humans, Cushing's syndrome, characterised by a massive cortisol excess without diurnal variation, provides an extreme example of the effects of glucocorticoids on glucose tolerance and lipoprotein metabolism [49].

It has been suggested that the health impact of social status is not the same in men and women [50]. Among men in the present study, the inverse gradients by grade in waist-hip ratio, glucose, insulin, low HDL cholesterol, raised triglycerides and fibrinogen are predominantly linear. The gradients among women are less consistent, particularly in the case of insulin, and reflect a tendency in the highest employment grade towards a poorer risk profile than predicted by simple analogy with men. A clear sex difference is evident for the low density lipoprotein fraction. At the study baseline [22] apoB was higher in the lower grades among women but not men. Parallel findings have been obtained with low density lipoprotein cholesterol at phase 3 .

Findings from the Whitehall II study baseline suggest that haemostatic function may be important in explaining the inverse socioeconomic status-coronary 
disease association [12]. In these follow-up data we replicate the employment grade-fibrinogen relationship and show that vWF levels are also inversely related to grade. It may be that haemostasis, as well as fibrinolysis [21], might be considered a candidate for addition to the constellation of factors which make up the metabolic syndrome. A high fibrinogen level is linked with a high waist-hip ratio, high fasting insulin and low HDL cholesterol in our study population.

Central obesity and other features of the metabolic syndrome, with the exception of resting blood pressure, increase in prevalence with each step down Civil Service employment grade strata. The findings are evidence of a distinctive socially patterned clustering of coronary risk factors. It remains to be seen whether membership of the higher-risk group defined at this study phase will be stable. As follow-up continues we will determine the extent to which the metabolic syndrome identifies those who later develop coronary disease, and is able to account for differences in disease incidence by employment grade. Our findings are consistent with behavioural, psychosocial and early life $[51,52]$ influences on the social distribution of coronary disease risk. Further investigation is required to examine the possible roles of psychosocial factors and altered neuroendocrine function in generating the distinct clustering of risk factors we have identified.

It is hoped that improved understanding of the biological basis of social inequalities in coronary risk will be useful in developing strategies for their reduction. Central obesity, its determinants and metabolic correlates may prove to be important considerations in this respect.

Acknowledgements. E. B. and M.S. are supported by the British Heart Foundation. M.M. is supported by an MRC research professorship. We thank all participating Civil Service departments and their welfare, personnel and establishment officers; the Civil Service Occupational Health Service; the Council of Civil Service Unions and all participating Civil Servants. We also thank Burton Singer, Linda Ashworth, Peter Lumb, John O'Brien, Mike Etherington and all members of the Whitehall II study team, in particular Rob Canner and Alexandra Lewis. The study is supported by grants from the Medical Research Council, British Heart Foundation, Health and Safety Executive, National Heart Lung and Blood Institute (2 RO1 HL36310), Agency for Health Care Policy Research (5 RO1 HS06516), the New England Medical Centre, Ontario Worker's Compensation Institute and the John D. and Catherine T. MacArthur Foundation Research Network on Successful Midlife Development. Smith-Kline Beecham supplied the glucose drink.

\section{References}

1. Marmot MG, Rose G, Shipley M, Hamilton PJS (1978) Employment grade and coronary heart disease in British civil servants. J Epidemiol Community Health 32: 244-249

2. Blane D, Brunner EJ, Wilkinson RG (1996) Health and social organization. Routledge, London
3. Marmot MG, Davey Smith G, Stansfeld S, et al. (1991) Health inequalities among British Civil Servants: the Whitehall II study. Lancet 337: 1387-1393

4. Davey Smith G, Neaton JD, Wentworth D, Stamler R, Stamler J (1996) Socioeconomic differentials in mortality risk among men screened for the Multiple Risk Factor Intervention Trial; I. white men. Am J Public Health 86: 486-496

5. Wilkinson RG (1995) "Variations" in health - The costs of government timidity. BMJ 311: 1177-1178

6. Brunner E (1997) Stress and the biology of inequality. BMJ 314: $1472-1476$

7. Davey Smith G, Shipley MJ, Rose G (1990) Magnitude and causes of socioeconomic differentials in mortality: further evidence from the Whitehall Study. J Epidemiol Community Health 44: 265-270

8. Hein HO, Suadicani P, Gyntelberg F (1992) Ischaemic heart disease incidence by social class and form of smoking: the Copenhagen male study - 17 years' follow-up. J Int Med 231: 477-483

9. Gregory J, Foster K, Tyler H, Wiseman M (1990) The Diet and Nutrition Survey of British adults. HMSO, London

10. OPCS (1995) Health Survey for England, 1993. HMSO, London

11. Stamler R, Shipley M, Elliott P, Dyer A, Sans S, Stamler J (1992) Higher blood pressure in adults with less education. Some explanations from INTERSALT. Hypertension 19: 237-241

12. Brunner EJ, Davey Smith G, Marmot M, Canner R, Beksinska M, O'Brien J (1996) Childhood social circumstances and psychosocial and behavioural factors as determinants of plasma fibrinogen. Lancet 347: 1008-1013

13. Larsson B, Svardsudd K, Welin L, Wilhelmsen L, Bjorntorp P, Tibblin G (1984) Abdominal adipose tissue distribution, obesity, and risk of cardiovascular disease and death: 13 year follow up of participants in the study of men born in 1913. BMJ 288: 1401-1404

14. Lapidus L, Bengtsson C, Larsson B, Pennert K, Rybo E, Sjostrom L (1984) Distribution of adipose tissue and risk of cardiovascular disease and death: a 12 year follow up of participants in the population study of women in Gothenburg, Sweden. BMJ 289: 1257-1261

15. Welin L, Svardsudd K, Wilhelmsen L, Larsson B, Tibblin G (1987) Analysis of risk factors for stroke in a cohort of men born in 1913. N Engl J Med 317: 521-526

16. Folsom AR, Kaye SA, Sellers TA, et al. (1993) Body fat distribution and 5-year risk of death in older women. JAMA 269: 483-487

17. Ohlson LO, Larsson B, Svardsudd K, et al. (1985) The influence of body fat distribution on the incidence of diabetes mellitus. 13.5 years of follow-up of the participants in the study of men born in 1913. Diabetes 34: 1055-1058

18. McKeigue PM, Shah B, Marmot MG (1991) Relation of central obesity and insulin resistance with high diabetes prevalence and cardiovascular risk in South Asians. Lancet 337: $382-386$

19. Kissebah AH, Vydelingum N, Murray R, et al. (1982) Relation of body fat distribution to metabolic complications of obesity. J Clin Endocrinol Metab 54: 254-260

20. Reaven GM (1993) Role of insulin resistance in human disease (syndrome X): an expanded definition. Ann Rev Med 44: 121-131

21. Juhan-Vague I, Thompson SJ, Jespersen J (1993) Involvement of the hemostatic system in the insulin resistance syndrome. Art Thromb 13: 1865-1873

22. Brunner EJ, Marmot MG, White IR, et al. (1993) Gender and employment grade differences in blood cholesterol, 
apolipoproteins and haemostatic factors in the Whitehall II study. Atherosclerosis 102: 195-207

23. Marmot MG, Adelstein AM, Bulusu L (1981) Cardiovascular mortality among immigrants to England and Wales. Postgraduate Medical Journal 57: 760-762

24. Beksinska M, Yea L, Brunner EJ (1995) Whitehall II study manual for screening examination 1991-93. DEPH, London

25. Friedewald WT, Levy RI, Fredrickson DS (1972) Estimation of the concentration of low-density lipoprotein cholesterol in plasma, without use of the preparative ultracentrifuge. Clin Chem 18: 499-502

26. WHO Study Group (1985) Diabetes mellitus: Report of a WHO Study Group. World Health Organization, Geneva

27. Laakso M (1993) How good a marker is insulin level for insulin resistance? Am J Epidemiol 137: 959-965

28. Davidson J, Woodbury MA, Pelton S, Krishnan R (1988) A study of depressive typologies using grade of membership analysis. Psychol Med 18: 179-189

29. Vague J (1956) The degree of masculine differentiation of obesities: a factor determining predisposition to diabetes, atherosclerosis, gout, and uric calculous disease. Am J Clin Nutr 4: $20-34$

30. Folsom AR, Burke GL, Ballew C, Jacobs DR, Haskell WL, Donahue RP (1989) Relation of body fatness and its distribution to cardiovascular risk factors in young blacks and whites. Am J Epidemiol 130: 911-924

31. Seidell JC, Bjorntorp P, Sjostrom L, Kvist H, Sannerstedt R (1990) Visceral fat accumulation in men is positively associated with insulin, glucose, and C-peptide levels, but negatively with testosterone levels. Metabolism 39: 897-901

32. Marmot MG, Shipley MJ, Rose G (1984) Inequalities in death - specific explanations of a general pattern. Lancet i: $1003-1006$

33. Fox J (ed) (1989) Health inequalities in European coutries. Gower Publishing Co Ltd, Aldershot

34. Kaplan GA, Keil JE (1993) Socioeconomic factors and cardiovascular disease: a review of the literature. Circulation 88: $1973-1998$

35. Heiss G, Haskell W, Mowery R, Criqui MH, Brockway M, Tyroler HA (1980) Plasma high-density lipoprotein cholesterol and socioeconomic status. Circulation 62 (Suppl IV): $108-115$

36. Larsson B, Bengtsson C, Bjorntorp P, et al. (1992) Is abdominal body fat distribution a major explanation for the sex difference in the incidence of myocardial infarction? Am J Epidemiol 135: 266-273

37. Eames M, Ben-Shlomo Y, Marmot MG (1993) Social deprivation and premature mortality: regional comparison across England. BMJ 307: 1097-1102
38. Marmot MG (1986) Social inequalities in mortality: the social environment. In: Wilkinson RG (ed) Class and health. Tavistock Publications, London, pp 21-34

39. Egolf B, Lasker J, Wolf S, Potvin L (1992) The Roseto effect: a 50-year comparison of mortality rates. Am J Public Health 82: 1089-1092

40. Bjorntorp P (1991) Visceral fat accumulation: the missing link between psychosocial factors and cardiovascular disease? J Int Med 230: 195-201

41. Ullah P (1990) The association between income, financial strain and psychological well-being among unemployed youths. J Occup Psychol 63: 317-330

42. Gallie D, Vogler C (1994) Labour market deprivation, welfare, and collectivism. In: Gallie D, Marsh C, Vogler C (eds) Social change and the experience of unemployment. Oxford University Press, Oxford, pp 299-317

43. Kopp MS, Skrabski A, Szedmak S (1995) Socioeconomic factors, severity of depressive symptomatology, and sickness absence rate in the Hungarian population. J Psychosom Res 39: 1019-1029

44. Brown GW (1986) Social support, self esteem and depression. Psychol Med 16: 813-831

45. Williams RB (1990) The role of the brain in physical disease. Folklore, normal science, or paradigm shift? JAMA 263: 1971-1972

46. Cook WW, Medley DM (1954) Proposed hostility and pharisaic- virtue scales for the MMPI. J Appl Psychol 38: 414-418

47. Kaye SA, Folsom AR, Jacobs DR, Hughes GH, Flack JM (1993) Psychosocial correlates of body fat distribution in black and white young adults. Int J Obes 17: 271-277

48. Sapolsky RM, Mott GE (1987) Social subordinance in wild baboons is associated with suppressed high density lipoprotein-cholesterol concentrations: the possible role of chronic social stress. Endocrinology 121: 1605-1610 "

49. Johnston DG, Alberti KGMM, Nattrass M, Barnes AJ, Bloom SR, Joplin GF (1980) Hormonal and metabolic rhythms in Cushing's syndrome. Metabolism 29: 1047-1051

50. Eaker ED, Pinsky J, Castelli WP (1992) Myocardial infarction and coronary death among women: psychosocial predictors from a 20 year follow-up of women in the Framingham study. Am J Epidemiol 135: 854-864

51. Bartley M, Power C, Blane D, Davey Smith G, Shipley M (1994) Birth weight and later socioeconomic disadvantage: evidence from the 1958 British cohort study. BMJ 309: 1475-1479

52. Hales CN, Barker DJP (1992) Type 2 (non-insulin-dependent) diabetes mellitus: the thrifty phenotype hypothesis. Diabetologia 35: 595-601 